\title{
0107 PREDICTORS OF RACE-DAY JOCKEY FALLS IN FLAT RACING IN AUSTRALIA
}

P L Hitchens*, C L Blizzard, G Jones, L Day, J Fell Correspondence: Menzies Research Institute, Private Bag 23 Hobart Tasmania 7001, Australia

\subsection{6/ip.2010.029215.107}

Objectives Riding racehorses is a hazardous occupation but, to date, there has not been a study of risk factors for falls to thoroughbred racing jockeys riding in flat races.

Methods Data on race-day falls were extracted from stewards' reports. Denominator data were provided by Racing Information Services Australia on races conducted in Australia from August 2002 until July 2006. Incidence rate ratios (IRRs) were estimated using Poisson regression. Analyses were stratified by race grade (maiden, class, open/restricted).

Results In multivariable analyses, factors associated with falls were female jockeys (IRR 1.11; 95\% CI 1.00 to 1.23), apprentice jockeys (1.51; 1.39 to 1.63$)$, amateur jockeys $(1.44 ; 1.11$ to 1.86), drier tracks, younger horse age, shorter race distance, lower field size and lower race grade (all $\mathrm{p}<0.05)$. The IRR's for five factors associated with falls differed by category of race grade: those for apprentice jockey, higher prize money and shorter race distance were greater in lower race grades, while those for fewer previous rides this meeting and drier track rating were greater in higher race grades. Female jockeys had a significantly higher incidence of falls when riding horses 


\section{IP Safety 2010 abstracts}

under 4 years of age in open/restricted races, and the effects of lower field size in maiden races, and of shorter races, were more pronounced for falls occurring prerace.

Conclusions We identified a range of factors associated with falls to thoroughbred racing jockeys riding in flat races that adds to the evidence base for formulating strategies to improve occupational health and safety standards in the thoroughbred racing industry. 